\title{
Optical coherence tomography imaging of chorioretinal folds associated with hypotony maculopathy following pars plana vitrectomy
}

This article was published in the following Dove Press journal:

International Medical Case Reports Journal

18 September 2015

Number of times this article has been viewed

\section{Basil K Williams Jr Jonathan S Chang Harry W Flynn Jr}

Department of Ophthalmology, Bascom Palmer Eye Institute, University of Miami Miller School of Medicine, Miami, FL, USA
Correspondence: Basil K Williams Jr

Department of Ophthalmology,

Bascom Palmer Eye Institute, University of Miami Miller School of Medicine, 900 NW 17th Street, Miami,

FL 33136, USA

Tel +l 3053266000

$\mathrm{Fax}+\mathrm{I} 3053266417$

Email basilkwilliams@gmail.com

\begin{abstract}
Chorioretinal folds may occur as a consequence of hypotony and can be a cause of vision loss when associated with macular involvement. In this report, the spectral domain ocular coherence tomography imaging of three patients with chorioretinal folds before and after management are presented. The cases had unique presentations and each underwent different management approaches, but the results included improved visual acuities and lessened chorioretinal folds.
\end{abstract}

Keywords: hypotony, chorioretinal folds, ocular coherence tomography

\section{Introduction}

Maculopathy associated with hypotony was first described by Dellaporta in $1954,{ }^{1}$ but the term "hypotony maculopathy" was coined by Gass in $1977 .{ }^{2}$ Chorioretinal folds can be identified with a number of conditions, but they are most frequently associated with hypotony. ${ }^{3}$ When folds extend to the macula, vision loss often results, leading to the term "hypotony maculopathy". These changes are perhaps most common following glaucoma surgery and have been more frequently reported during the last 20 years since the initiation of antimetabolite adjuncts for trabeculectomy. Conservative management may lead to spontaneous resolution, but some may require surgical intervention.

If hypotony is the cause, normalizing the intraocular pressure (IOP) will often lead to resolution of the folds. A subset of patients may require additional interventions including pressure patch, anterior chamber injection of viscoelastic, cryotherapy to a filtering bleb or to a cyclodialysis cleft, conjunctival compression sutures, or wound revision. ${ }^{3,4}$ Furthermore, delayed normalization of the IOP may result in permanent macular chorioretinal changes and poor vision. ${ }^{3}$ Three cases of hypotony maculopathy following pars plana vitrectomy (PPV) documented by spectral domain ocular coherence tomography (SD-OCT) are presented with differing underlying causes. The visual acuity improved after normalization of the IOP and lessening of the folds was confirmed by SD-OCT. The management of these clinical situations is discussed.

\section{Case reports Case I}

A 47-year-old Mexican-American man was treated for a macula-involving retinal detachment in the right eye. He was pseudophakic with a history of high myopia in both eyes and a prior manifest refraction of $-22.00 \mathrm{D}$ prior to cataract surgery. The best-corrected visual acuity (BCVA) was 20/400 and a rhegmatogenous retinal 
detachment with several posterior breaks was noted. The patient underwent successful retinal reattachment surgery using 23-gauge PPV with silicone oil tamponade. Silicone oil was selected because of the patient's need to urgently return to Mexico after surgery. At 5 months postoperatively, the BCVA was 20/30, IOP was $12 \mathrm{mmHg}$, the retina was attached, and there were no chorioretinal folds noted.

At 1 year following surgery, he maintained a BCVA 20/30 and IOP $12 \mathrm{mmHg}$, and the silicone oil was removed. In the immediate postoperative period, the eye was noted to have a BCVA of 2/200 and an IOP of $3 \mathrm{mmHg}$. An ultrasound study demonstrated an irregular retinal contour. Seven days later, an air bubble was injected to pressurize the eye with hypotony-induced chorioretinal folds. A repeat fluid-air exchange was performed in the clinic 9 days after surgery. The following day, the BCVA was 20/400 with IOP $4 \mathrm{mmHg}$ and associated chorioretinal fold in the macula was documented by SD-OCT (Figure 1A). He was treated with oral prednisone $30 \mathrm{mg}$ and topical difluprednate. Two weeks following surgery, the BCVA was 20/200 with an improved IOP of 10 $\mathrm{mmHg}$ and a persistent fold. Two months after the silicone oil removal, the patient returned with a BCVA of 20/25 and IOP $9 \mathrm{mmHg}$. The chorioretinal fold was markedly improved but not completely absent (Figure 1B).

\section{Case 2}

A 74-year-old Hispanic woman presented after sustaining an accidental kick in the head from an infant resulting in a ruptured globe and extruded intraocular lens (IOL) in the right eye. The BCVA was light perception in the right eye and 20/25 in the left eye, and the IOP was $5 \mathrm{mmHg}$ and $20 \mathrm{mmHg}$ in each eye, respectively. The patient underwent surgical repair for the 3-clock-hour superior scleral rupture from the site of prior cataract surgery and attained BCVA of 20/200 with an IOP of $17 \mathrm{mmHg}$ at 2 weeks postoperatively. A 23-gauge
PPV was performed for persistent vitreous hemorrhage, and the scleral wound was revised at that time. By postoperative month 1 , her hypotony had resolved with an IOP of $30 \mathrm{mmHg}$ and she underwent secondary IOL placement with scleral fixated IOL and 25-gauge PPV. Over the next 3 months, the patient had sustained hypotony and chorioretinal folds by SD-OCT and a BCVA of 20/50 (Figure 2A and 2B). She again underwent revision of the initial scleral wound with resolution of the hypotony and by 1 month postoperative, her vision returned to 20/30, her IOP normalized to $16 \mathrm{mmHg}$, and her chorioretinal folds by SD-OCT resolved (Figure 2C and 2D).

\section{Case 3}

An 86-year-old Caucasian man was referred for management of a dislocated IOL in the left eye 15 years after cataract surgery. The IOL was in the posterior pole on initial examination with a BCVA of 20/40 and an IOP of $11 \mathrm{mmHg}$. He underwent a 23-gauge PPV with lens removal and secondary sutured IOL placement. The eye was found to be hypotonous, with pressures not exceeding $4 \mathrm{mmHg}$, during the first postoperative month. The patient also had a hyphema and vitreous hemorrhage with vision fluctuating from 20/400 to hand motions. He was found to have chorioretinal folds by SD-OCT (Figure 3A) and received an intravitreal injection of triamcinolone acetonide $4 \mathrm{mg} / 0.1 \mathrm{~mL}$ with minimal improvement in IOP over the following 2 months. Contact B-scan ultrasonography demonstrated a cyclodialysis cleft possibly exacerbated by a subluxed IOL. He was treated conservatively with atropine $1 \%$ and prednisolone acetate $1 \%$ without improvement. He then underwent pupilloplasty and repositioning of the IOL and sequential rounds of diode laser to the cleft over the following 2 months with slow increase in pressure from approximately $1 \mathrm{mmHg}$ to $10 \mathrm{mmHg}$. The maculopathy persisted for several months
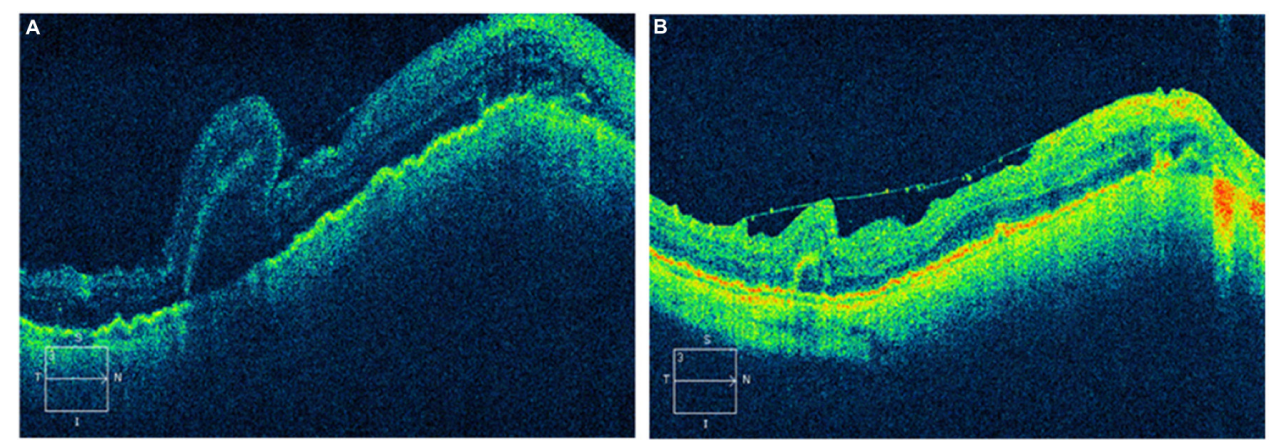

Figure I After surgical repair of the retinal detachment and subsequent removal of silicone oil, the postoperative SD-OCT demonstrating chorioretinal folds is shown in (A) with improvement but not complete resolution of the folds in (B).

Abbreviation: SD-OCT, spectral domain ocular coherence tomography. 

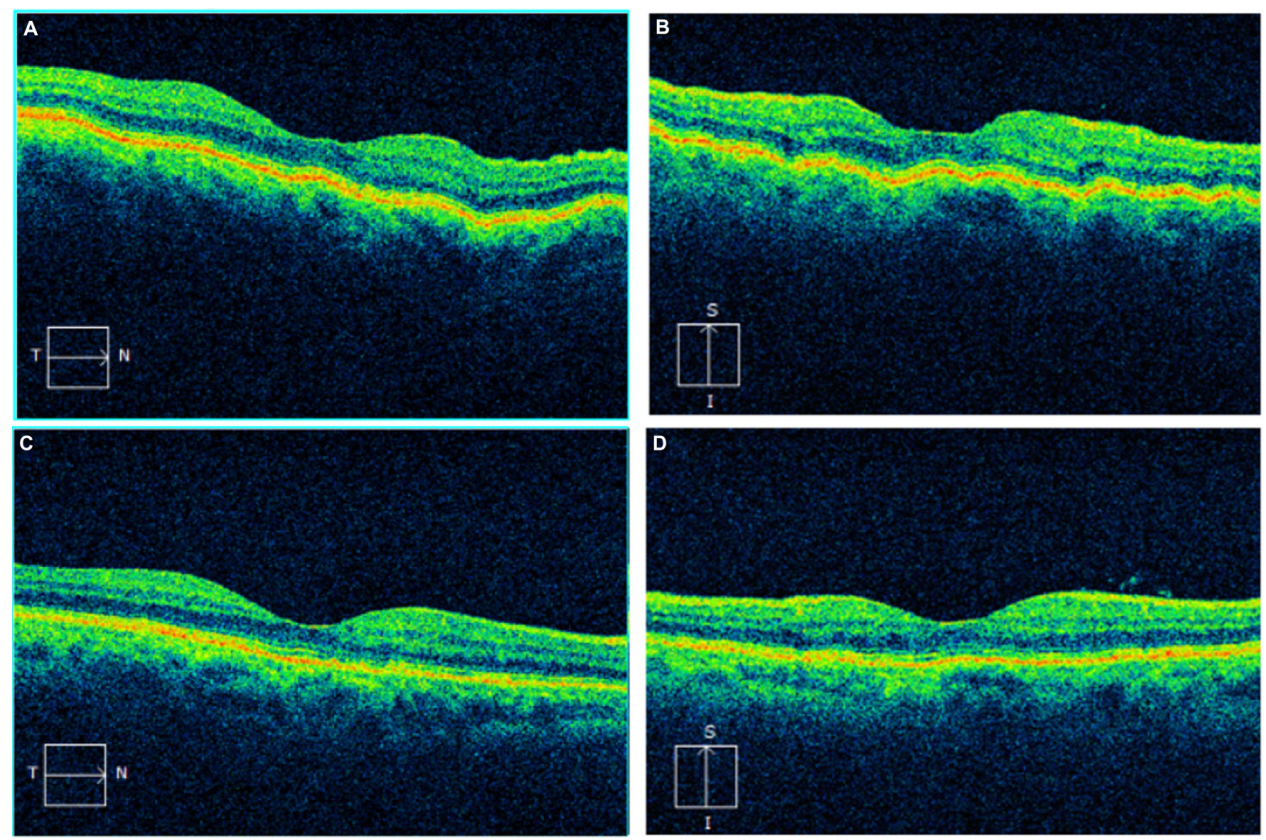

Figure 2 The horizontal line scan from the SD-OCT of the right eye of the patient demonstrates subtle chorioretinal folds (A). The vertical line scan more clearly demonstrates the chorioretinal folds (B). On both the horizontal and vertical line scans taken after treatment, there is a resolution of the folds (C and $\mathbf{D})$.

Abbreviation: SD-OCT, spectral domain ocular coherence tomography.

after the cleft closure with a near visual acuity of Jaeger 2 . His pressure gradually decreased again, and he was treated with a 23-gauge PPV, membrane peeling, Healon injection, and cryotherapy to the cyclodialysis cleft to induce elevation in IOP. However, his IOP rose to $48 \mathrm{mmHg}$. A vitreous chamber tap was performed but rebound increases in IOP occurred, and the patient was taken back for a 23-gauge PPV and Healon removal 3 days after initial injection. Postoperatively, his IOP remained in the low-teens and vision stabilized. His chorioretinal folds by SD-OCT resolved (Figure 3B) over
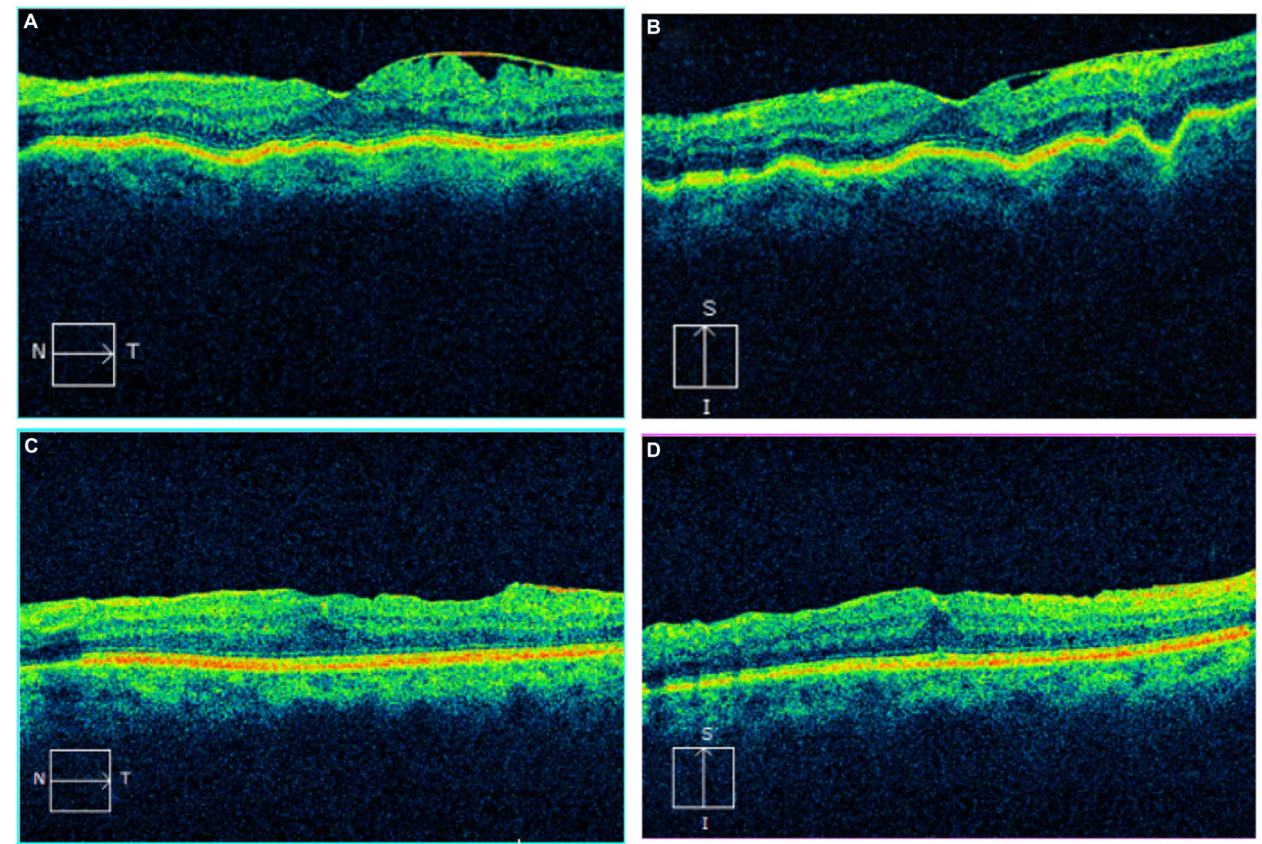

Figure 3 The horizontal line scan from the SD-OCT of the left eye of the patient demonstrates subtle chorioretinal folds (A). The vertical line scan more clearly demonstrates the chorioretinal folds (B). On both the horizontal and vertical line scans taken after treatment, there is a resolution of the folds (C and $\mathbf{D}$ ). Abbreviation: SD-OCT, spectral domain ocular coherence tomography. 
the ensuing 2 months, and 17 months after his most recent surgery, the BCVA had improved to 20/40 with a stable IOP ranging from 9 to $12 \mathrm{mmHg}$.

\section{Discussion}

Chorioretinal folds were diagnosed clinically but confirmed by the use of fluorescein angiography prior to the routine use of SD-OCT. A strictly retinal fold could be distinguished from a chorioretinal fold by the lack of involvement of the linear hyper and hypofluorescence of the choroid in the early stages. Since the advent and documentation by SD-OCT, chorioretinal folds that were previously unrecognized have become better documented, allowing improved correlation with visual acuity and IOP. ${ }^{5}$ In addition to diagnostic assistance, SD-OCT may aid in the follow-up of chorioretinal folds. Clinically, patients with chorioretinal folds caused by hypotony are more likely to show swelling of the choroid around the optic nerve head and may produce concentric folding that can be confused for papilledema. ${ }^{2}$ Management typically is directed to the source of hypotony in each individual case. With resolution of the hypotony, the macular chorioretinal folds may become less prominent or disappear. However, in prolonged hypotony, the folds may be evidenced by permanent pigmented lines corresponding to the troughs of the folds.

In patients who underwent transconjunctival bleb resuturing for hypotony after trabeculectomy, there was no statistically significant difference in IOP or BCVA when comparing patients with short-term hypotony to those with long-term hypotony. ${ }^{6}$ Long-term hypotony was defined as greater than 4 months. In that study, chorioretinal folds were only recorded in approximately half of the patients during the hypotonous period demonstrating that hypotony does not always lead to a maculopathy but also that these patients may have transiently had folds that spontaneously resolved between follow-up periods. There is the possibility that subtle chorioretinal folds were underdiagnosed in the absence of SD-OCT. These findings also suggest that medical management can be successful while reserving surgical intervention for more severe hypotony and folds. In the current series, one of the three patients had documented chorioretinal folds for over a year prior to resolution and still regained baseline visual acuity and normalization of IOP. Furthermore, evidence has been presented in the form of case reports that delayed intervention, as much as 7 years, may still result in a good visual outcome. ${ }^{7}$

The chorioretinal folds that present in hypotony maculopathy are often oriented horizontally, radiating temporally from the optic nerve. In order to identify the folds on SD-OCT, vertical line scans may better illustrate the folds. Cases 2 and 3 in this series presented with horizontal folds that would not have been identified if only focusing on the horizontal line scans. This observation emphasizes the importance of two-dimensional sectioning and analysis when evaluating OCT in these patients.

The three cases of hypotony-induced chorioretinal folds following vitrectomy presented here highlight varied management approaches for resolution of the folds. Chorioretinal folds resulting from hypotony maculopathy may resolve spontaneously as the IOP normalizes as evidenced by case 1 . In scenarios in which hypotony does not resolve with medical therapy, cases 2 and 3, surgical intervention may be considered and can result in good visual outcomes. Despite different treatment regimens, all the three cases retained good visual acuity (20/25-20/40).

\section{Acknowledgments}

This research is in part funded by NIH Center Core Grant P30EY014801, Research to Prevent Blindness Unrestricted Grant, Department of Defense (DOD - Grant\#W81XWH09-1-0675).

\section{Disclosure}

The authors report no conflicts of interest in this work.

\section{References}

1. Dellaporta A. [Creasing of retina in hypotonia]. Klin Monbl Augenheilkd Augenarztl Fortbild. 1954;125(6):672-678.

2. Gass JDM. Chorioretinal folds. In: Stereoscopic Atlas of Macular Diseases: Diagnosis and Treatment. 2nd ed. Saint Louis: The CV Mosby Company; 1977:147-154.

3. Costa VP, Arcieri ES. Hypotony maculopathy. Acta Ophthalmol Scand. 2007;85(6):586-597.

4. Cohen SM, Flynn HW Jr, Palmberg PF, Gass JD, Grajewski AL, Parrish RK 2nd. Treatment of hypotony maculopathy after trabeculectomy. Ophthalmic Surg Lasers. 1995;26(5):435-441.

5. Giuffre G, Distefano MG. Optical coherence tomography of chorioretinal and choroidal folds. Acta Ophthalmol Scand. 2007;85(3):333-336.

6. Eha J, Hoffmann EM, Pfeiffer N. Long-term results after transconjunctival resuturing of the scleral flap in hypotony following trabeculectomy. $\mathrm{Am}$ J Ophthalmol. 2013;155(5):864-869.

7. Delgado MF, Daniels S, Pascal S, Dickens CJ. Hypotony maculopathy: improvement of visual acuity after 7 years. Am J Ophthalmol. 2001; 132(6):931-933. 
International Medical Case Reports Journal

Dovepress

\section{Publish your work in this journal}

The International Medical Case Reports Journal is an international, peer-reviewed open-access journal publishing original case reports from all medical specialties. Previously unpublished medical posters are also accepted relating to any area of clinical or preclinical science. Submissions should not normally exceed 2,000 words or

4 published pages including figures, diagrams and references. The manuscript management system is completely online and includes a very quick and fair peer-review system, which is all easy to use. Visit $\mathrm{http}: / / \mathrm{www}$.dovepress.com/testimonials.php to read real quotes from published authors.

Submit your manuscript here: http://www.dovepress.com/international-medical-case-reports-journal-journal 